\title{
Pro- and antioxidant activity of curcuminoids with lecithin in sunflower oil
}

\author{
Sameera A. Rege, Shamim A. Momin
}

\begin{abstract}
Department of Oils, Oleochemicals and Surfactants Technology, Institute of Chemical Technology, Nathalal Parekh Marg, Matunga (East), Mumbai, India.
\end{abstract}

\author{
Keywords: \\ Curcuminoids \\ Synergism \\ Tautomerism \\ Structure-activity \\ Sunflower \\ Oil
}

\section{Article history:}

Received 25.06.2017

Received in revised form

01.09 .2017

Accepted 05.09.2017

\section{Corresponding author:}

Shamim A. Momin

E-mail:

samomin@rediffmail.com

DOI: $10.24263 / 2304-$

974X-2017-6-3-9

\section{Abstract}

Introduction. Curcumin present as a major constituent amongst curcuminoids in turmeric has attracted significant attention due to wide range of biological and pharmaceutical activities. It reveals various therapeutic activities such as antiinflammatory, nematocidal, anti-parasitic, antispasmodic and anticarcinogenic. Additionally, it is a powerful scavenger of reactive oxygen species. On the other hand, the pro-oxidant effect of curcumin has also been observed.

Materials and methods. The study has been carried out to evaluate the activity of curcuminoids in crude and refined sunflower oil containing synthetic antioxidant. The various blends of oil were prepared. The oxidative stability of oil blends was checked at $60^{\circ} \mathrm{C}$ for 30 days at regular interval of 5 days according to the AOCS Official Methods by peroxide value (in $\mathrm{meq} / \mathrm{kg}$ ), $p$-anisidine value and total oxidation (Totox) value (in $\mathrm{meq} / \mathrm{kg}$ ).

Results and discussion. The tendency of curcumin to exhibit keto-enol tautomerism determines its physicochemical and antioxidant properties. It has been observed that curcuminoids showed noticeable dissimilar behavior in both oils. The hydrogen atom donation in case of curcumin is from the active methylene group, which exists only in keto form. The keto form predominates in neutral and acidic solutions whereas the enol form predominates in alkaline solution. In alkaline medium, curcumin undergoes degradation. The same theory is also applicable to other two curcuminoids, i.e., demethoxycurcumin and bisdemethoxycurcumin. Hence, it becomes crucial to maintain the curcuminoids in keto form to be used as antioxidant.

In crude sunflower oil, because of the presence of free fatty acids, curcuminoids did not undergo degradation imparting marginal antioxidant activity. Lecithin chelated metal ions present in oil, which promote oxidation of oil thereby inhibiting the autoxidation of oil. However, the synergistic activity of curcuminoids and lecithin revealed remarkable antioxidant activity.

In refined sunflower oil containing tertiary butylhydroquinone (TBHQ), curcuminoids showed pro-oxidant activity due to lack of acidic medium. Lecithin exhibited synergistic activity with TBHQ in refined sunflower oil. Nevertheless, the pro-oxidant effect of curcuminoids is not observed in presence of lecithin and TBHQ. Thus, the lecithin and TBHQ stabilized refined sunflower oil in presence of curcuminoids.

Conclusion. The structure-activity relationship plays an important role in determining the activity (antioxidant or prooxidant) of a particular compound. Thus, a constituent should exist in a proper structural form to be used as an antioxidant. 


\section{- Food Technology -}

\section{Introduction}

Turmeric, the rhizome of plant Curcuma longa Linn has been widely used as a spice. Besides, it is used to colour food beverages like cheese, butter to increase its nutritive value [1] and in some medicinal preparations [2, 3]. The multiple traditional uses of turmeric in folk medicine have fostered research on the same. The dry rhizome of turmeric contains curcuminoids namely curcumin, demethoxycurcumin and bisdemethoxycurcumin [4]. Commercial preparations of curcuminoids usually contain approximately $77 \%, 17 \%$ and $3 \%$ of curcumin, demethoxycurcumin and bisdemethoxycurcumin respectively. Several studies in recent years have shown that curcumin has antioxidant, anti-inflammatory, antimicrobial, anti-bacterial, anti-parasitic, anti-mutagen and anticancer properties [5, 6]. It is believed that curcumin is a potent agent against many diseases such as anorexia, coughs, diabetes, hepatic disorders, rheumatism and Alzheimer disease [7-9]. Curcumin and avocado-soya bean unsaponifiables based antioxidant supplements are beneficial to get relief from knee osteoarthritis [10]. The other two curcuminoids namely demethoxycurcumin and bisdemethoxycurcumin also possess antioxidant activity [11]. The effectiveness of curcuminoids as an anti-depressive agent [12] and in wound healing [13] has also been proved. The safety of the Curcuma longa has been studied in various animal models $[14,15]$ and it is clear that turmeric is not toxic even at high doses in laboratory animals.

Curcumin has a strong antioxidant activity in food systems and in biological systems as well $[16,17]$. Curcumin was proved to be considerably more effective than other spices in its ability to prevent lipid peroxidation. Its antioxidant effect was eight times more powerful than vitamin E [18] and it was significantly more effective in preventing lipid peroxide formation than the synthetic antioxidant, butylated hydroxytoluene (BHT) [19]. On the contrary, moderate pro-oxidant activity of curcumin has been observed in ghee [20].

Structurally, curcumin is 1,7-bis(4-hydroxy-3-methoxyphenyl)-1,6-heptadiene-3,5dione. It undergoes keto-enol tautomerism [21]. The tautomers are shown in Figure 1. Hydroxyl groups of the benzene rings, double bonds in the alkene part and the central $\beta$ diketone moiety are suggested to be likely responsible for the high beneficial activities of curcumin $[22,23]$. The mode of action (i.e., either antioxidant or pro-oxidant) of curcumin depends upon the form (viz. keto or enol) in which it exists [24].

Sunflower oil being rich source of essential fatty acids is susceptible to autoxidation [25]. Hence, it cannot be stored without addition of antioxidant. In the view of the importance of curcumin, the objective of the study was to evaluate the activity of curcuminoids in crude and refined sunflower oil containing tertiary butylhydroquinone (TBHQ). The synergistic activity of curcuminoids with other natural antioxidants is illustrated [26, 27]. However, curcuminoids do not show remarkable synergistic effect in the presence of lipophobic antioxidant like ascorbic acid in water-in-oil emulsion [28]. The existence of other constituents in the substrate has a profound effect on the activity of the antioxidant [29]. The effect of natural constituents present in crude oil on the behavior of curcuminoids was investigated. Further, the mode of action of curcuminoids in presence of TBHQ alone in refined oil was examined. To our knowledge, this is the first report to investigate the effect of synthetic antioxidant on the activity of curcuminoids in refined sunflower oil. The study is extended further to investigate the effect of lecithin on the activity of curcuminoids in both oils. The outcome of the study was that the activity of curcuminoids differs in crude and refined sunflower oil containing TBHQ. In addition, the results led to the conclusion that the presence of other constituents had a remarkable effect on the activity of curcuminoids. 


\section{Materials and methods}

\section{Materials}

Crude sunflower oil (CSFO) and refined sunflower oil (RSFO) without any synthetic antioxidant were received as gift samples from M/s Cargill India Pvt. Ltd., New Delhi. Curcuminoids powder was obtained from Kancor India Ltd., Angamaly South, India. The purity of curcuminoids was $96 \%$ with three components namely curcumin $(59.3 \%)$, demethoxycurcumin $(20.0 \%)$ and bisdemethoxycurcumin $(16.7 \%)$ as analyzed by HPTLC (Desaga Sarstedt Gruppe, Applicator AS 30 and Densitometer CD 60) as per the previously mentioned method [30]. Soy lecithin was procured from M/s V.R. Chemicals, Mumbai. All other chemical reagents and solvents were obtained from s.d. fiNE-CHEM LiMiTEd, Mumbai.

\section{Study of antioxidant activity}

The various blends of oil containing curcuminoids $(50 \mathrm{ppm})$, lecithin $(1.5 \% \mathrm{w} / \mathrm{v})$, TBHQ (150 ppm, $200 \mathrm{ppm}$ ) and their combinations were prepared. The oxidative stability of oil blends was checked according to the AOCS Official Methods [31] by Schaal Oven Test (Method $\mathrm{Cg} 5-97$ ) at $60{ }^{\circ} \mathrm{C}$ for 30 days at regular interval of 5 days by peroxide value (in meq $/ \mathrm{kg}$ ) (PV, Method Cd 8-53), $p$-anisidine value ( $p$-A.V., Method Cd 18-90) and total oxidation (Totox) value (in meq/kg) (Method Cg 3-91). All the experiments were carried out in triplicate and the values were expressed as arithmetic mean of the experiments along with standard deviation. The accelerated oxidative stability study of the oil blends is carried out to increase the rate of oxidation. At $60{ }^{\circ} \mathrm{C}$, though the rate of oxidation is increased, the mechanism of oxidation is the same as that at ambient temperature.

The antioxidant activities of natural antioxidants were compared with the corresponding control samples under the same conditions. The relative antioxidant activities were compared using Oxidative Factor (OXF) for antioxidants based on mean peroxide value of triplicate experiments using following formula [32],

$$
O F X=\frac{\left(P V_{\text {final }}-P V_{\text {initial }}\right)_{\text {antioxidant }}}{\left(P V_{\text {final }}-P V_{\text {initial }}\right)_{\text {control }}}
$$

where PVs indicate the mean values of all triplicate determinations of the peroxide value.

\section{Results and discussion}

Jovanovic et al. [24] concluded that the two phenolic hydroxyl groups in curcumin are very weak hydrogen atom donors. The hydrogen atom donation in case of curcumin is from the active methylene group unlike other antioxidants which donate hydrogen atom from phenolic hydroxyl group to exhibit antioxidant activity. The active methylene group in curcumin exists only in keto form (Figure 1). In neutral and acidic solutions (from $\mathrm{pH} 3$ to 7), the keto form predominates. In keto form, since methylene group is in-between two electron withdrawing carbonyl groups, the delocalization of the unpaired electrons on the oxygens of carbonyl groups takes place. This results in weakening of $\mathrm{C}-\mathrm{H}$ bond of methylene group. The carbon radical so formed after donation of hydrogen atom gets 
stabilized by resonance with neighboring carbonyl groups. Thus, a stabilized radical is formed, preventing the degradation of curcumin. Hence, curcumin exclusively acts as a hydrogen atom donor.<smiles>[R]c1cc(/C=C/C(=O)CC(=O)/C=C/c2ccc(O)c([R2])c2)ccc1O</smiles><smiles>[R]c1cc(/C=C/C(=O)/C=C(O)/C=C/c2ccc(O)c([R2])c2)ccc1O</smiles>

Enol form

Figure 1. Tautomers of curcuminoids: $\mathrm{R} 1=\mathrm{R} 2=-\mathrm{OCH}_{3}$; Curcumin $\mathrm{R} 1=-\mathrm{H}, \mathrm{R} 2=-\mathrm{OCH}_{3} ;$ Demethoxycurcumin $\mathrm{R} 1=\mathrm{R} 2=-\mathrm{H}$; Bisdemethoxycurcumin

The enol form of curcumin predominates above $\mathrm{pH} 8$ and the active methylene group diminishes completely. In alkaline medium, curcumin is known to undergo degradation to form ferulic acid, feruloylmethane that further hydrolyzed to vanillin and acetone [33]. The formation of vanillin and ferulic acid takes place via peroxide formation [34]. Thus, the degradation of curcumin leads to increase in the peroxide value of the substrate [26].

The same theory is also applicable to other two curcuminoids, i.e., demethoxycurcumin and bisdemethoxycurcumin. Thus, it becomes necessary to maintain curcuminoids in keto form by providing reserved acidity in hydrophobic medium to utilize the antioxidant activity.

\section{Effect of curcuminoids in synergism with lecithin on oxidative stability of CSFO}

The crude vegetable oils extracted from oil bearing materials naturally contain free fatty acids formed during pretreatment and extraction processes [35]. The synergism between curcuminoids and lecithin was studied in crude oil (CSFO), i.e., in presence of tocopherols as natural antioxidants and free fatty acids those were anticipated to stabilize the curcuminoids by acting as an acidic buffer. The observations from Table 1 illustrate the synergism of curcuminoids and lecithin in CSFO that showed good antioxidant activity (Figure 2). 
Effect of curcuminoids and lecithin on oxidative stability of CSFO at $60^{\circ} \mathrm{C}$

\begin{tabular}{|c|c|c|c|c|c|c|c|c|c|}
\hline \multirow[t]{2}{*}{ 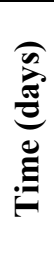 } & \multirow{2}{*}{$\begin{array}{c}\text { CSFO } \\
\text { Totox }^{\dagger}\end{array}$} & \multicolumn{2}{|c|}{$\begin{array}{c}\text { CSFO + } \\
200 \text { ppm } \\
\text { TBHQ }\end{array}$} & \multicolumn{2}{|c|}{$\begin{array}{c}\text { CSFO + } \\
50 \text { ppm } \\
\text { curcuminoids }\end{array}$} & \multicolumn{2}{|c|}{$\begin{array}{c}\text { CSFO + } \\
\text { 1.5\% lecithin }\end{array}$} & \multicolumn{2}{|c|}{$\begin{array}{c}\text { CSFO + } \\
1.5 \% \text { lecithin } \\
+ \\
50 \text { ppm } \\
\text { curcuminoids }\end{array}$} \\
\hline & & OXF & Totox $^{\dagger}$ & OXF & Totox $^{\dagger}$ & OXF & $\operatorname{Totox}^{\dagger}$ & OXF & $\operatorname{Totox}^{\dagger}$ \\
\hline 5 & $41.2 \pm 1.4$ & 0.42 & $24.9 \pm 1.0$ & 0.63 & $41.7 \pm 1.5$ & 0.42 & $18.9 \pm 0.9$ & 0.69 & $25.1 \pm 0.4$ \\
\hline 10 & $57.4 \pm 1.2$ & 0.28 & $27.1 \pm 1.3$ & 0.74 & $51.2 \pm 1.7$ & 0.45 & $32.0 \pm 1.4$ & 0.42 & $30.7 \pm 0.7$ \\
\hline 15 & $80.7 \pm 1.5$ & 0.26 & $30.2 \pm 1.1$ & 0.78 & $64.8 \pm 2.1$ & 0.58 & $50.9 \pm 1.8$ & 0.39 & $38.8 \pm 0.9$ \\
\hline 20 & $106.8 \pm 1.6$ & 0.29 & $38.9 \pm 1.8$ & 0.81 & $88.3 \pm 1.9$ & 0.66 & $74.1 \pm 1.5$ & 0.42 & $51.9 \pm 1.1$ \\
\hline 25 & $124.2 \pm 1.9$ & 0.28 & $44.7 \pm 1.5$ & 0.83 & $104.0 \pm 2.2$ & 0.71 & $89.6 \pm 2.1$ & 0.46 & $60.6 \pm 0.9$ \\
\hline 30 & $138.1 \pm 2.3$ & 0.28 & $49.4 \pm 1.7$ & 0.84 & $116.5 \pm 2.8$ & 0.74 & $102.0 \pm 2.5$ & 0.49 & $67.6 \pm 1.3$ \\
\hline
\end{tabular}

${ }^{\dagger}$ The Totox values (in meq/kg) given are means of three consecutive experiments \pm standard deviations

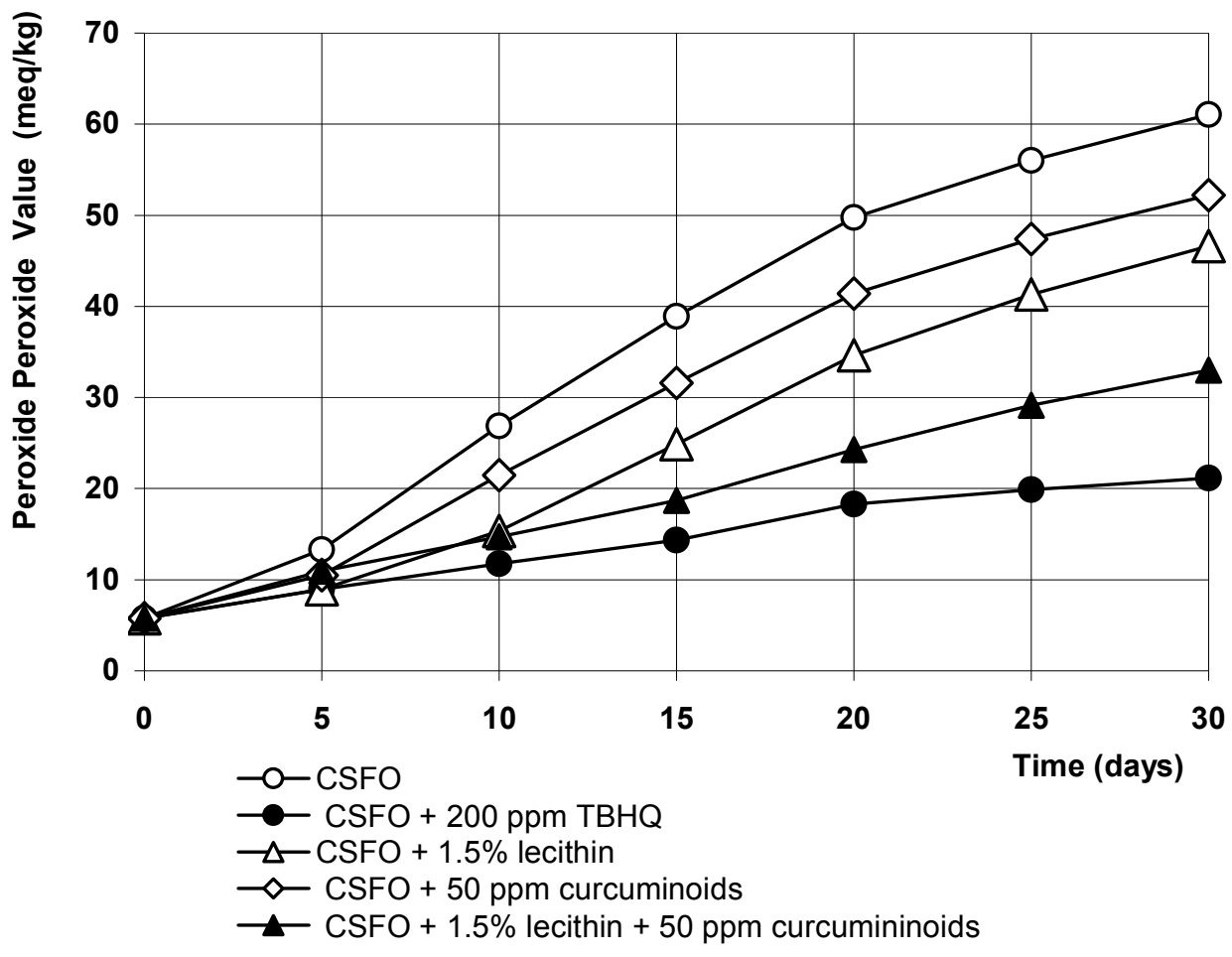

Figure 2. Effect of curcuminoids and lecithin on oxidative stability (peroxide formation) of CSFO at $60^{\circ} \mathrm{C}$ 
Generally, oil contains polyvalent metals ions catched during processing, which further promote autoxidation of oil on storage. Lecithin chelated these metal ions thereby inhibiting the formation of radicals and peroxides. Hence, CSFO in presence of lecithin gave lower peroxide value than CSFO. Lecithin being an emulsifier can additionally prevent the autoxidation of oil by its action as an oxygen barrier at oil/air interface. These effects inhibited the formation of radicals and peroxides due to metal ions, consequently reducing the peroxide formation at initial stage. However, the same effects were incapable to control autoxidation due to radicals formed at later stage.

Moreover, the free fatty acids present in CSFO (acid value, $3.4 \mathrm{mg} \mathrm{KOH} / \mathrm{g}$ ) stabilized curcuminoids, eventually imparting antioxidant effect. Hence, curcuminoids gave marginal antioxidant activity in CSFO. At the same time, the curcuminoids cannot terminate the activity of metal ions and peroxide formation was more than that of CSFO containing lecithin.

The synergistic activity of lecithin and curcuminoids gave good antioxidant activity, as lecithin promoted metal ion chelation and curcuminoids act as antioxidant. As a result, the autoxidation of oil was inhibited by two different ways. It was observed that this synergistic effect is less than TBHQ.

\section{Effect of curcuminoids in synergism with lecithin on oxidative stability of RSFO in presence of TBHQ}

The fatty acids from CSFO are removed in subsequent refining process. As discussed in our previous study, curcuminoids showed pro-oxidant effect in refined sunflower oil [26] due to absence of free fatty acids. The behaviour of curcuminoids in presence of lecithin in RSFO was evaluated. The acid value of RSFO is very low, i.e., $0.29 \mathrm{mg} \mathrm{KOH} / \mathrm{g}$. It can be seen from Table 2 that initially curcuminoids underwent degradation. However, lecithin scavenged radicals formed due to curcuminoids along with that generated by RSFO and continued to act as an antioxidant. As a result, the peroxide value was reduced below to the control after 20 days. Lecithin chelated metal ions by its usual phenomenon but the amount $1.5 \%$ was inadequate to scavenge free radicals generated by the combined process of autoxidation of oil as well as curcuminoids.

Effect of curcuminoids and lecithin on oxidative stability of RSFO at $60^{\circ} \mathrm{C}$

Table 2

\begin{tabular}{|c|c|c|c|c|c|}
\hline \multirow[t]{2}{*}{ Time (days) } & \multirow{2}{*}{$\begin{array}{c}\text { RSFO } \\
\text { Totox }^{\dagger}\end{array}$} & \multicolumn{2}{|c|}{$\begin{array}{c}\text { RSFO + } \\
1.5 \% \text { lecithin }\end{array}$} & \multicolumn{2}{|c|}{$\begin{array}{c}\text { RSFO }+ \\
1.5 \% \text { lecithin }+ \\
50 \text { ppm curcuminoids }\end{array}$} \\
\hline & & OXF & Totox $^{\dagger}$ & OXF & Totox $^{\dagger}$ \\
\hline 5 & $17.5 \pm 0.7$ & 1.03 & $18.5 \pm 1.2$ & 2.17 & $36.9 \pm 1.0$ \\
\hline 10 & $24.2 \pm 0.5$ & 0.74 & $19.6 \pm 1.4$ & 1.57 & $39.0 \pm 1.3$ \\
\hline 15 & $31.0 \pm 1.0$ & 0.69 & $22.1 \pm 1.0$ & 1.71 & $50.1 \pm 1.7$ \\
\hline 20 & $47.3 \pm 1.2$ & 0.64 & $31.1 \pm 1.8$ & 1.12 & $52.6 \pm 1.5$ \\
\hline 25 & $57.3 \pm 1.9$ & 0.58 & $34.7 \pm 1.7$ & 0.98 & $58.2 \pm 1.4$ \\
\hline 30 & $77.3 \pm 2.2$ & 0.46 & $39.0 \pm 1.5$ & 0.85 & $72.5 \pm 1.9$ \\
\hline
\end{tabular}

${ }^{\dagger}$ The Totox values (in $\mathrm{meq} / \mathrm{kg}$ ) given are means of three consecutive experiments \pm standard deviations 
The antioxidant effect of curcuminoids and lecithin was also studied in presence of TBHQ. The control sample was RSFO containing $150 \mathrm{ppm}$ TBHQ in this case. Figure 3 reveals the pronounce pro-oxidant effect of curcuminoids in presence of TBHQ that was shown by higher totox values for curcuminoids as compared to control sample (Table 3). It signifies that, $150 \mathrm{ppm}$ TBHQ was potentially insufficient to stabilize curcuminoids in RSFO. The combined activity of TBHQ and lecithin was found to be unaffected in presence of curcuminoids. In other words, curcuminoids did not show the pro-oxidant effect in presence of lecithin and TBHQ.

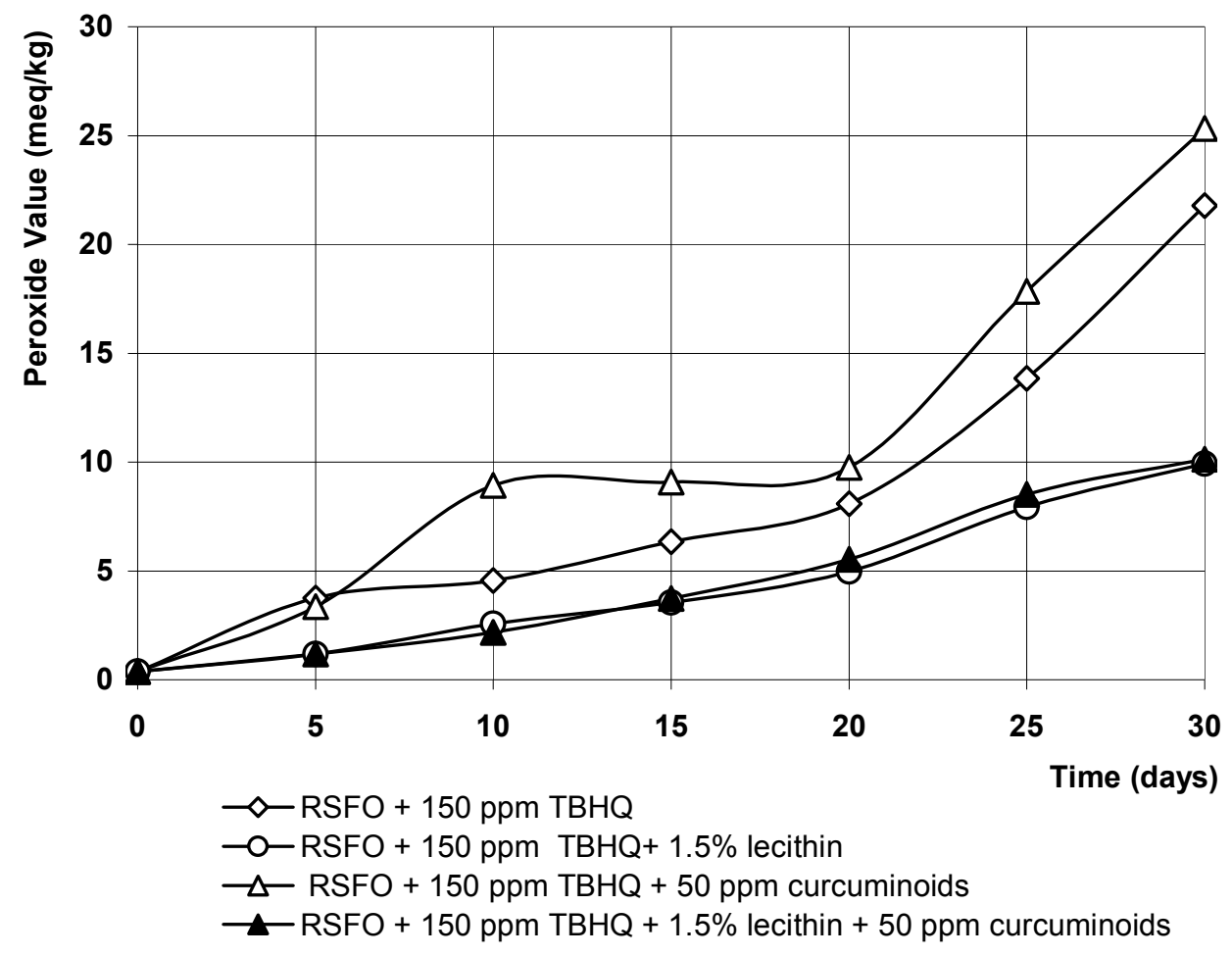

Figure 3. Effect of curcuminoids and lecithin with TBHQ on oxidative stability (peroxide formation) of RSFO at $60^{\circ} \mathrm{C}$

Lecithin showed synergistic antioxidant activity with TBHQ as shown with other phenolic antioxidants [36, 37]. It is quite possible that curcuminoids may undergo degradation in this blend as well. But the pro-oxidant effect of curcuminoids was not observed. This may be due to lecithin that chelated polyvalent metal ions and TBHQ that scavenged free radicals, generated by oxidation of oil and curcuminoids. Hence, the combined effect of lecithin and TBHQ stabilized RSFO even in presence of curcuminoids. 
Effect of curcuminoids and lecithin on oxidative stability of $\operatorname{RSFO}(\mathrm{T})$ at $60^{\circ} \mathrm{C}$

\begin{tabular}{|c|c|c|c|c|c|c|c|}
\hline Time (days) & RSFO(T) & \multicolumn{2}{|c|}{$\begin{array}{c}\text { RSFO(T) }+ \\
\text { 50 ppm } \\
\text { curcuminoids }\end{array}$} & \multicolumn{2}{c|}{$\begin{array}{c}\text { RSFO(T) }+ \\
\mathbf{1 . 5 \%} \text { lecithin }\end{array}$} & \multicolumn{2}{c|}{$\begin{array}{c}\text { RSFO(T) + } \\
\text { 1.5\% lecithin }+ \\
\text { 50 ppm } \\
\text { curcuminoids }\end{array}$} \\
\cline { 2 - 8 } & Totox $^{\dagger}$ & OXF & Totox $^{\dagger}$ & OXF & Totox $^{\dagger}$ & OXF & Totox $^{\dagger}$ \\
\hline 5 & $10.8 \pm 0.2$ & 0.89 & $15.7 \pm 0.7$ & 0.24 & $5.5 \pm 0.8$ & 0.24 & $3.9 \pm 0.4$ \\
\hline 10 & $13.7 \pm 0.4$ & 2.05 & $21.1 \pm 1.2$ & 0.52 & $7.5 \pm 0.7$ & 0.43 & $6.5 \pm 0.6$ \\
\hline 15 & $17.1 \pm 0.3$ & 1.46 & $23.9 \pm 1.0$ & 0.53 & $9.9 \pm 1.1$ & 0.56 & $9.6 \pm 0.7$ \\
\hline 20 & $21.2 \pm 0.5$ & 1.22 & $25.5 \pm 1.5$ & 0.60 & $12.6 \pm 0.7$ & 0.67 & $13.3 \pm 1.4$ \\
\hline 25 & $34.1 \pm 0.9$ & 1.30 & $41.8 \pm 2.2$ & 0.56 & $18.2 \pm 1.4$ & 0.60 & $19.3 \pm 2.2$ \\
\hline 30 & $50.2 \pm 1.1$ & 1.17 & $56.9 \pm 1.7$ & 0.45 & $22.1 \pm 2.4$ & 0.46 & $22.7 \pm 2.7$ \\
\hline
\end{tabular}

${ }^{\dagger}$ The Totox values (in meq $/ \mathrm{kg}$ ) given are means of three consecutive experiments \pm standard deviations

$\mathrm{RSFO}(\mathrm{T})$ is the refined sunflower oil with added $150 \mathrm{ppm}$ TBHQ

\section{Conclusion}

The antioxidant or pro-oxidant effect of a compound depends upon its structure. This is particularly demonstrated in case of curcuminoids that showed contrast activity in keto and enol forms. Curcuminoids exhibited antioxidant activity provided they should remain in keto form. Curcuminoids showed antioxidant effect in crude oil due to the presence of free fatty acids that contributed to the stabilization of curcuminoids by maintaining them in keto form. In refined oil with TBHQ, curcuminoids were unable to maintain themselves in keto form exhibiting pro-oxidant effect due to the absence of free fatty acids. Curcuminoids showed synergistic antioxidant activity with lecithin in crude oil, which was not shown in refined oil even in presence of synthetic antioxidants like TBHQ. It can be concluded that it is crucial to maintain the proper form of a compound to utilize its antioxidant effect.

\section{Acknowledgement}

This study was financially supported by Technical Education Quality Improvement Programme (TEQIP), Government of India and World Bank.

\section{References}

1. Rege S.A., Momin S.A., Wadekar S.D., Bhowmick D.N. (2013), Formulation of a functional fat spread stabilized by natural antioxidants and emulsifiers, Malaysian Journal of Nutrition, 19(1), pp. 121-129. 
2. Govindarajan V.S. (1980), Turmeric: Chemistry, technology, and quality, Critical Reviews in Food Science and Nutrition, 12(3), pp. 199-301.

3. Ammon H.P., Wahl, M.A. (1991), Pharmacology of Curcuma longa, Planta Medica, 57(1), pp. 1-7.

4. Limtrakul P., Anuchapreeda S., Buddhasukh D. (2004), Modulation of human multidrugresistance MDR-1 gene by natural curcuminoids, BioMed Central Cancer, 4(13), pp. 1-6.

5. Gorman A.A., Hamblett I., Srinavasan V.S., Wood P.D. (1994), Curcumin-derived transients: a pulsed laser and pulse radiolysis study, Photochemistry and Photobiology, 59(4), pp. 389-398.

6. Khanna N. (1999), Turmeric-nature's precious gift, Current Science, 76, pp. 1351-1356.

7. Aggarwal B.B., Kumar A., Bharti A.C. (2003), Anticancer potential of curcumin: Preclinical and clinical studies, Anticancer Research, 23(1A), pp. 363-398.

8. Ono K., Hasegawa K., Naiki H., Yamada M. (2004), Curcumin has potent antiamyloidogenic effects for Alzheimer's $\beta$-amyloid fibrils in vitro, Journal of Neuroscience Research, 75(6), pp. 742-750.

9. Jain S.K., Rains J., Jones K. (2006), Effect of curcumin on protein glycosylation, lipid peroxidation, and oxygen radical generation in human red blood cells exposed to high glucose levels, Free Radical Biology and Medicine, 41(1), pp. 92-96.

10. Grover A.K., Samson S.E. (2016), Benefits of antioxidant supplements for knee osteoarthritis: rationale and reality, Nutrition Journal, 15(1), pp. 1-13.

11. Jayaprakasha G.K., Rao L.J., Sakariah K.K. (2006), Antioxidant activities of curcumin, demethoxycurcumin and bisdemethoxycurcumin, Food Chemistry, 98(4), 720-724.

12. Panahi Y., Badeli R., Karami G.R., Sahebkar A. (2015), Investigation of the efficacy of adjunctive therapy with bioavailability-boosted curcuminoids in major depressive disorder, Phytotherapy Research, 29(1), pp. 17-21.

13. Kant V., Gopal A., Pathak N.N., Kumar P., Tandan S.K., Kumar D. (2014), Antioxidant and anti-inflammatory potential of curcumin accelerated the cutaneous wound healing in streptozotocin-induced diabetic rats, International Immunopharmacology, 20(2), pp. 322330 .

14. Shankar T.N., Shantha N.V., Ramesh H.P., Murthy I.A., Murthy V.S. (1980), Toxicity studies on turmeric: Acute toxicity studies in rats, guinea pigs and monkeys, Indian Journal of Experimental Biology, 18(1), pp. 73-75.

15. Qureshi S., Shah A.H., Ageel A.M. (1992), Toxicity studies on Alpinia galanga and Curcuma longa, Planta Medica, 58(2), pp. 124-127.

16. Haung M.T., Ferraro T. (1992), Phenolic compounds in food and cancer prevention, In Houng M.T., Ho C.T., Lee C.Y. (Eds), Phenolic Compounds in Food and Their Effects on Health II. Antioxidants and Cancer Prevention, Vol. 507, ACS Symposium Series, pp. 834. Washington DC: American Chemical Society.

17. Sokmen M., Khan M.A. (2016), The antioxidant activity of some curcuminoids and chalcones, Inflammopharmacology, 24(2), pp. 81-86.

18. Reddy A.C.P., Lokesh B.R. (1992), Studies on spice principles as antioxidants in the inhibition of lipid peroxidation of rat liver microsomes, Molecular Cell Biochemistry, 111(1), pp. 117-124.

19. Majeed M., Badmaev V., Shivakumar U., Rajendran R. (1995), Curcuminoids-Antioxidant Phytonutrients, Piscataway, New Jersey: Nutriscience Publishers, Inc.

20. Semwal A.D., Sharma G.K., Arya, S.S. (1997), Antioxygenic activity of turmeric (Curcuma longa) in sunflower oil and ghee, Journal of Food Science Technology, 34(1), pp. 67-69.

21. (2004), Curcumin, Chemical and Technical Assessment, 61st JECFA. pp. 1-8. Available at: $\mathrm{ftp}: / / \mathrm{ftp}$.fao.org/es/esn/jecfa/cta/CTA_61_Curcumin.pdf

22. Osawa T., Namiki M. (1985), Natural antioxidants isolated from eucalyptus leaf waxes, Journal of Agricultural and Food Chemistry, 33(5), pp. 777-780. 
23. Ruby A.J., Kuttan G., Babu K.D., Rajasekharan K.N., Kuttan R. (1995), Antitumor and oxidant activity of natural curcuminoids, Cancer Letters, 94(1), pp. 79-83.

24. Jovanovic S.V., Steenken S., Boone C.W., Simic M.G. (1999), H-atom transfer is a preferred antioxidant mechanism of curcumin, Journal of the American Chemical Society, 121(41), pp. 9677-9681.

25. Knothe, G., Kenar, J.A., Gunstone F.D. (2007), Chemical Properties, In Gunstone F.D., Harwood J.L., Dijkstra A.J. (Eds), The Lipid Handbook, pp. 535-541. LLC: Taylor and Francis Group.

26. Rege S.A., Momin S.A., Bhowmick D.N., Pratap A.P. (2012), Stabilization of emulsion and butter like products containing essential fatty acids using kalonji seeds extract and curcuminoids, Journal of Oleo Science, 61(1), pp. 11-16.

27. Rege S.A., Momin S.A. (2017), Synergistic antioxidant activity of capsicum oleoresin, lecithin and curcuminoids in sunflower oil, International Journal of Food Processing Technology, 4(1), pp. 6-11.

28. Rege, S.A., Momin, S.A., Bhowmick, D.N. (2015), Effect of ascorbic acid on the oxidative stability of water-in-oil emulsion in presence of lipophilic antioxidants, International Journal of Food Properties, 18(2), pp. 256-259.

29. Sameera, A.R., Shamim, A.M. (2017), Effect of purification on the antioxidant activity of ajowan extract in refined sunflower oil, Journal of Food and Nutritional Disorders, 6(2), pp. $1-5$.

30. Chearwae W., Anuchapreeda S., Nandigama K., Ambudkar S.V., Limtrakul P. (2004), Biochemical mechanism of modulation of human P-glycoprotein (ABCB1) by curcumin I, II and II purified from Turmeric powder, Biochemical Pharmacology, 68(10), pp. 20432052.

31. Firestone D. (1994), American Oil Chemists' Society, Official methods and recommended practices of the American Oil Chemists' Society, 4th Ed. AOCS Press: Champaign, IL.

32. Ghada A., Vassiliki O. (2007), Antioxidant properties and composition of Majorana syriaca extracts, European Journal of Lipid Science and Technology, 109(3), pp. 247-255.

33. Tonnesen H.H., Karlsen J. (1985), Studies of curcumin and curcuminoids: V. Alkaline degradation of curcumin, Zeitschriftfür Lebensmittel-Untersuchung und -Forschung, 180(2), pp. 132-134.

34. Masuda T., Hidaka K., Shinohara A., Maekawa T., Takeda Y. (1999), Chemical studies on antioxidant mechanism of curcuminoid: Analysis of radical reaction products from Curcumin, Journal of Agricultural and Food Chemistry, 47(1), pp. 71-77.

35. Anderson D.A. (2005), Primer on Oils Processing Technology, In Shahidi F. (Ed), Bailey's Industrial Oil and Fat Products, 6th ed. Vol. 5. pp. 1-56. New Jersey: John Wiley and Sons Inc.

36. Koga T., Terao T. (1995), Phospholipids increase radical-scavenging activity of vitamin E in a bulk model system, Journal of Agricultural and Food Chemistry, 43(6), pp. 14501454.

37. Saito H., Ishihara K. (1997), Antioxidant activity and active sites of phospholipids as antioxidants, Journal of the American Oil Chemists' Society, 74(12), pp. 1531-1536. 